\title{
Coat color determination by miR-137 mediated down-regulation of microphthalmia-associated transcription factor in a mouse model
}

\author{
CHANGSHENG DONG, ${ }^{1,5,6}$ HAIDONG WANG, ${ }^{1,5}$ LINLI XUE, $^{2}$ YANJUN DONG, $^{1,3}$ LEI YANG, $^{1}$ RUIWEN FAN, $^{1}$ \\ XIUJU YU, ${ }^{1}$ XUE TIAN, ${ }^{1}$ SHUHUI MA, ${ }^{1}$ and GEORGE W. SMITH ${ }^{1,4}$ \\ ${ }^{1}$ College of Animal Science and Veterinary Medicine, ${ }^{2}$ College of Information, Shanxi Agricultural University, Taigu, PC 030801, Shanxi, China \\ ${ }^{3}$ Nephrology Division, Baylor College of Medicine, Houston, Texas 77030, USA \\ ${ }^{4}$ Laboratory of Mammalian Reproductive Biology and Genomics, Departments of Animal Science and Physiology, \\ Michigan State University, East Lansing, Michigan 48824, USA
}

\begin{abstract}
Coat color is a key economic trait in wool-producing species. Color development and pigmentation are controlled by complex mechanisms in animals. Here, we report the first production of an altered coat color by overexpression of miR-137 in transgenic mice. Transgenic mice overexpressing miR-137 developed a range of coat color changes from dark black to light color. Molecular analyses of the transgenic mice showed decreased expression of the major target gene termed MITF and its downstream genes, including TYR, TYRP1, and TYRP2. We also showed that melanogenesis altered by miR-137 is distinct from that affected by UV radiation in transgenic mice. Our study provides the first mouse model for the study of coat color controlled by miRNAs in animals and may have important applications in wool production.
\end{abstract}

Keywords: miR-137; coat color; melanogenesis

\section{INTRODUCTION}

Traditionally, white wool holds the highest value in wool industry due to the fact that white wool can be dyed to different colors for commercialized products. Nevertheless, applications of chemical dyes damage human health and pollute the environment. Thus, a natural-colored wool is much preferred in the modern industry. Coat color is determined mainly by the synthesis and distribution of melanin, which is the main contributor to pigmentation in skin, hair bulbs, and the color of eyes (De Luca et al. 1988; Zhu et al. 2010). At the cellular level, melanin is synthesized in melanocytes, unique cells located in the basal layer of the epidermis and regularly interspersed among the basal keratinocytes. The development of melanocytes and melanogenesis is regulated by many genes. Among them, microphthalmia-associated transcription factor (MITF) is

\footnotetext{
${ }^{5}$ These authors contributed equally to this work.

${ }^{6}$ Corresponding author

E-mail dongchangsheng2010@hotmail.com

Article published online ahead of print. Article and publication date are at http://www.rnajournal.org/cgi/doi/10.1261/rna.033977.112.
}

a master regulator of melanocyte development and melanogenesis in melanocytes (Fitzpatrick and Breathnach 1963; Fitzpatrick 1965; Lin et al. 2007; Schallreuter et al. 2008). MITF regulates the transcription of three major pigmentation enzymes, tyrosinase (TYR), tyrosine related protein-1 (TYRP1), and tyrosine related protein-2 (TYRP2; dopachrometautomerase, DCT) (Bentley et al. 1994; Hemesath et al. 1994; Yasumoto et al. 1994; Zhu et al. 2010). Overexpression of MITF increases the production of TYR, TYRP1, and DCT (Yasumoto et al. 1997). The coat color of C57BL/6J mice whitens, because of a 1-nucleotide mutation in the DNA binding region of MITF (Kurita et al. 2005). Mutations in MITF phosphorylation sites also lead to white or spotted white coat color (Bauer et al. 2009). So control of the expression and function of MITF is potentially critical for producing engineered animals that have multi-colors in their wool fibers.

MicroRNAs (miRNAs) down-regulate gene expression post-transcriptionally and provide a fine-tuning of the target genes in almost all the organs of various animals. Skinexpressed miRNAs may play a key role in the control of skin development, coat color, and melanogenesis. One of the first identified skin-expressed miRNAs is miR-203, and this miRNA was revealed to be overexpressed in patients with psoriasis 
(Sonkoly et al. 2007). The murine ortholog of miR-203 also has important functions in the regulation of epidermal differentiation (Yi et al. 2008). A previous study identified 105 miRNAs with conserved expression in differentiating hair follicles of the goat and sheep (Zhang et al. 2007). Zhu et al. (2010) investigated the expression of nine miRNAs in the skin of alpacas with brown versus white coat color, and identified potential mRNA targets for identified miRNAs among coat color genes.

Accumulating studies on the expression profiles of miRNAs and their target genes in cancer cells have revealed a marked alteration of various oncogenic miRNAs (oncomiRs) and a general regulation of the target gene transcripts by the miRNAs (Lu et al. 2005; Calin and Croce 2006; Garzon et al. 2006). Furthermore, it has been reported that several miRNAs, including miR-137 target MITF, in melanoma cell lines (Bemis et al. 2008; Segura et al. 2009), and overexpression of miR-137 in melanoma cell lines down-regulates MITF expression (Bemis et al. 2008). Although miR-137 has been found to target MITF in cancer cells, to date, an animal model for examining the function of this miRNA in animal coat color regulation is lacking. In this study, we hypothesized that miR-137, though regulation of MITF, may play a key role in coat color determination. We show that transgenic mice overexpressing miR-137 have altered coat color, thus providing a useful mouse model for the study of molecular regulation of pigmentation.

\section{RESULTS}

\section{Production of transgenic mice that overexpress miR-137}

To determine the candidate genes responsible for pigmentation and use them to generate transgenic mouse models for the study of coat color regulation, we screened 34 candidate genes of melanogenesis signaling pathway in the KEGG PATHWAY database (http://www.kegg.jp/kegg/). Among them, we selected MITF as our target gene since it is a known transcription factor essential for the biosynthesis of tyrosinase and tyrosinase-related enzymes, which affect melanogenesis and coat color (Bentley et al. 1994; Hemesath et al. 1994; Yasumoto et al. 1994; Zhu et al. 2010). Bioinformatics predictions in publicly available algorithms (TargetScan 4.1, www.targetscan.org; miRBase, microrna. sanger.ac.uk) indicated that MITF may be targeted by multiple miRNAs, including miR-137 (Fig. 1A). Considering that miR-137 was recently reported to down-regulate MITF in melanoma cell lines (Bemis et al. 2008), we selected this miRNA as the first candidate miRNA for overexpression in transgenic mice.

Before generating transgenic mice, we designed an appropriate expression construct and tested if transfection of the construct overexpressing miR-137 results in MITF down-regulation in cultured melanocytes. The pre-miR-
137 was synthesized and cloned into a mammalian expression vector, pcDNA 6.2-GW/EmGFPmiR (Invitrogen), resulting in a construct that contains a CMV promoter driving the expression of green fluorescent protein (GFP) and the introduced miR-137. To overexpress miR-137, three copies of the pre-miR-137 were introduced in this construct (Fig. 1B). Logarithmic phase primary melanocyte cells were transfected with the construct using Liposome 2000. Cells transfected with the miR-137 construct had a 17-fold higher expression of miR-137 in comparison to the cells transfected with the vector control or the nontransfected cells (Fig. 1C). Although MITF mRNA levels were not affected by the overexpression of miR-137, MITF protein levels were significantly reduced by 0.5 -fold below the control group (Fig. 1D,E), suggesting a strong translational repression of MITF was induced by the overexpressed miR137. Furthermore, TYR, TYRP1, and TYRP2, three key genes for melanin production downstream from MITF, were also reduced by 0.54 -fold, 0.41 -fold, and 0.64 -fold, respectively, at the mRNA levels (Fig. $1 \mathrm{~F}-\mathrm{H}$ ) and by 0.44 -fold, 0.6-fold, and 0.73 -fold, respectively, at the protein levels (Fig. 1D). These data strongly support that miR-137 overexpression reduces MITF translation and expression of MITF downstream genes linked to pigmentation and that the construct for miR-137 overexpression is appropriate for the production of transgenic mice.

Transgenic mice were generated by pronuclear microinjection. We obtained five transgenic founder animals. Nine litters of $\mathrm{F} 1$ generation, containing a total of 54 mice, were used for genotyping analysis by PCR (Fig. 2A), and percentages of positive transgenic mice (miR-137) were $65 \%$. Expression of the transgene was further confirmed by real-time polymerase chain reaction (PCR). The levels of both pre-miR-137 and mature miR-137 in the miR-137-transgenic mice were significantly higher than those in the wild-type control mice.

\section{Altered coat color in the miRNA-137 transgenic mice}

Breeding of transgenic founders with wild-type mice revealed that there was no significant difference between the transgenic and wild-type mice in reproduction or survival rate. Yet, dramatic changes in coat color were observed in transgenic mice. Of the 120 transgenic mice, 68 mice were gray, seven mice were brown, and the remaining 45 were black (Fig. 2B). Transgenic mice showed a lower level of melanin than did the control mice. The transgenic mice with gray color showed the lowest melanin production and highest levels of miR-137 expression, and the brown and the black transgenic mice showed slightly reduced melanin production and lower, but still elevated, miR-137 expression relative to that of the wild-type control animals (Fig. 2C). These data suggest that different levels of miR-137 expression in transgenic mice may result in different coat colors through down-regulation of melanin production (Fig. 2D). 
A

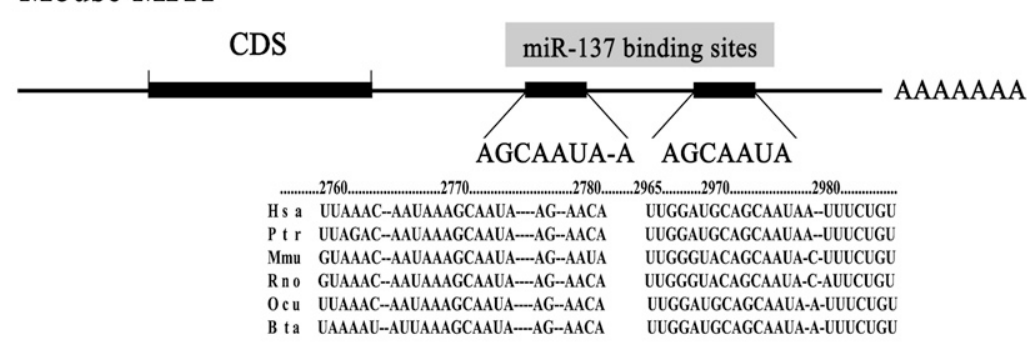

B
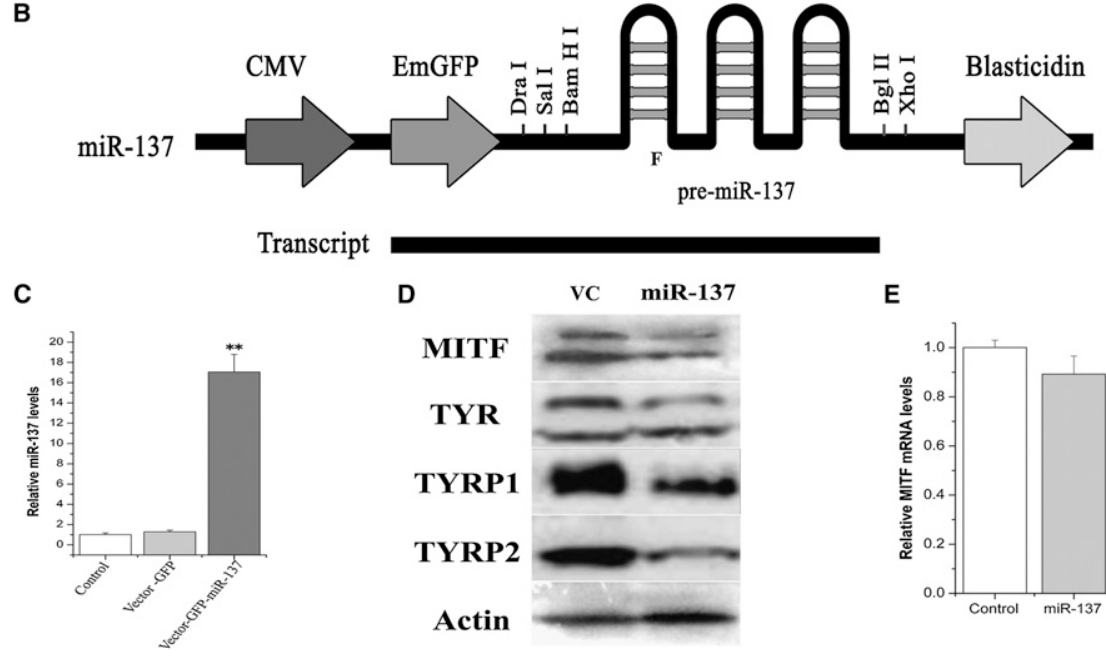

Transcript
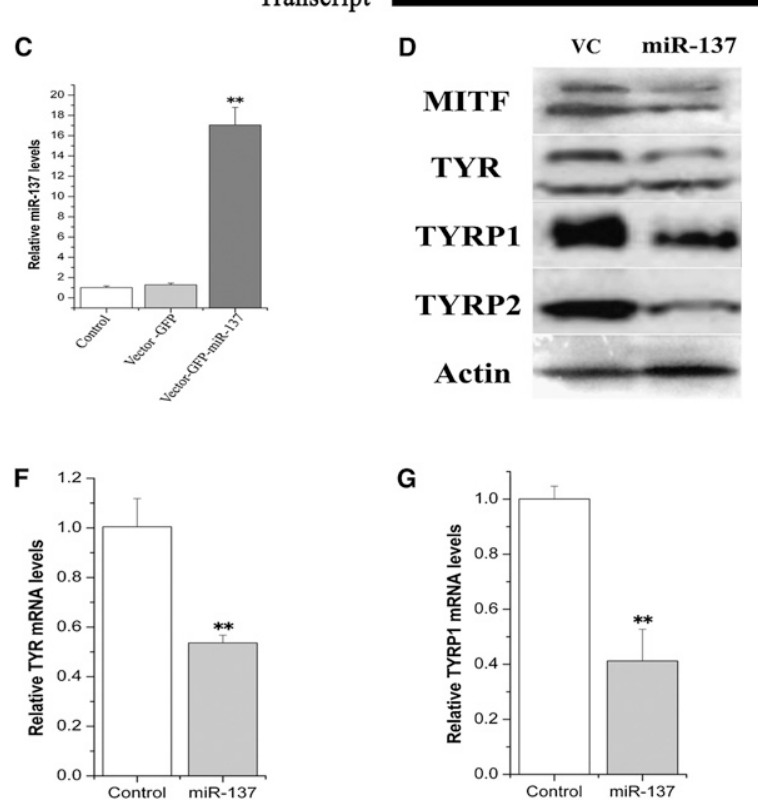

G

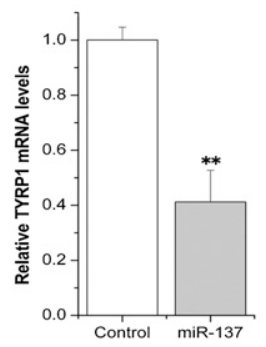

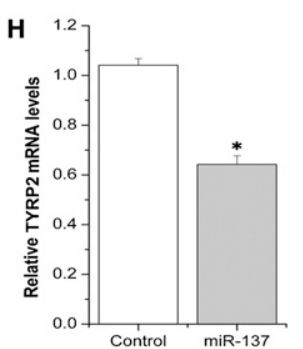

FIGURE 1. MiR-137 targets MITF directly in primary mice melanocyte cell line. $(A)$ Bioinformatic analysis showing miR-137 target binding sites in 3' UTR of MITF. Hsa indicates human; Ptr, chimpanzee; mmu, mouse; Rno, rat; Ocu, rabbit; and Bta, cow. (B) Diagram of the construct expressing EmGFP and three copies of pre-miR-137. (C) miR-137 mRNA levels in melanocytes transfected with the miR-137 construct and vector control. (D) Western analysis of MITF, TYR, TYRP1, and TYRP2 protein expression in melanocytes overexpressing miR-137 versus vector control (VC). $\beta$-actin was used as a protein loading control. $(E-H)$ Real-time PCR analysis of MITF, TYR, TYRP1, and TYRP2, respectively, mRNA expression in melanocytes overexpressing miR-137 versus vector control. $\left.\left(^{*}\right) P<0.05,{ }^{* *}\right) P<0.01$.

\section{Altered expression of coat color genes in skin of miR-137 transgenic mice}

To determine the effects of overexpression of miR-137 on coat color, we compared the expression of genes in the skin of transgenic mice and wild-type control mice using DNA microarray (Supplemental Fig. S1). Expression of many genes was changed, suggesting that miR-137 has a wide impact on gene expression directly or indirectly (Fig. 3A). Interestingly, MITF had no significant changes in its transcriptional

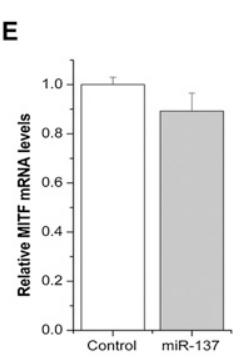

expression compared with the control mice, as shown by either microarray or real-time PCR (Fig. 3C), suggesting that miR-137 does not trigger the degradation of MITF mRNAs and may trigger the translational repression of its mRNAs. Indeed, immunohistochemistry and Western blotting analyses showed MITF proteins were significantly reduced in the miR-137 transgenic mice (Fig. 3B,G). The MITF downstream enzymes TYR, TYRP1, and TYRP2 were also down-regulated to different levels in the transgenic mice (Fig. 3D-F). Results indicate overexpression of miR-137 blocked the production of MITF protein, which repressed the transcription of TYR, TYRP1, and TYRP2 (Fig. 3B) and resulted in little synthesis of melanin and light coat color.

\section{Melanogenesis controlled by miR- 137 is a distinct pathway from that affected by ultraviolet radiation in transgenic mice}

Previous studies showed that $\alpha$-melanocyte-stimulating hormone ( $\alpha-\mathrm{MSH})$ could suppress the expression of miR137 and increase the expression of MITF in melanocytes, thus activating its downstream pathway and pigment synthesis (Bemis et al. 2008). We investigated this pathway and found that $\alpha-\mathrm{MSH}$ and melanocortin 1 receptor (MC1R) expression in transgenic mice was higher than that of the wild-type littermates (Fig. $4 \mathrm{~A}-\mathrm{C})$. Overexpression of miR-137 reduced pigmentation in transgenic mice. Ultraviolet (UV) may induce the synthesis of melanin in skins of the transgenic mice, which elevates the expression of MC1R and stimulates the keratinocytes to secrete $\alpha$-MSH to enhance the $\alpha-\mathrm{MSH}$ pathway on melanogenesis.

To confirm $\alpha-\mathrm{MSH}$ and MC1R are increased by UV but not by miR-137, we overexpressed miR-137 by transfecting logarithmic-phase primary melanocytes with the miR-137 overexpression construct using Liposome 2000. The results showed that production of $\alpha-M S H$ and MC1R in the miR137 overexpression cells is the same as in the control cells. Production of $M C 1 R$ in cells overexpressing miR-137 plus UV treatment was increased by 1.51 -fold, while that in the cells treated with UV alone was increased by 1.8 -fold, compared to the control cells. In contrast, $\alpha-M S H$ mRNA 
A

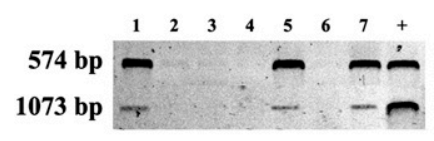

B

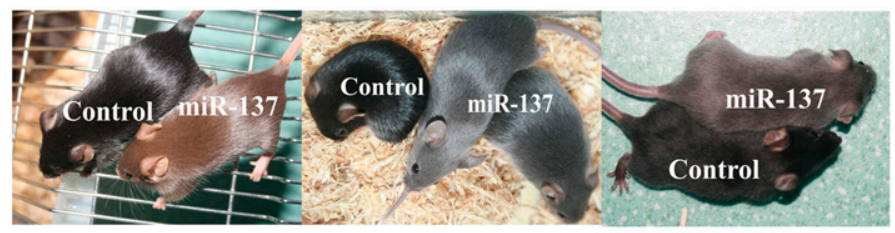

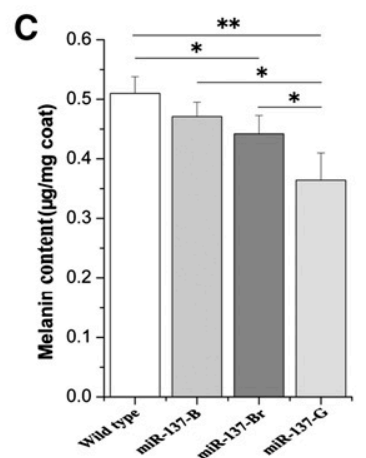

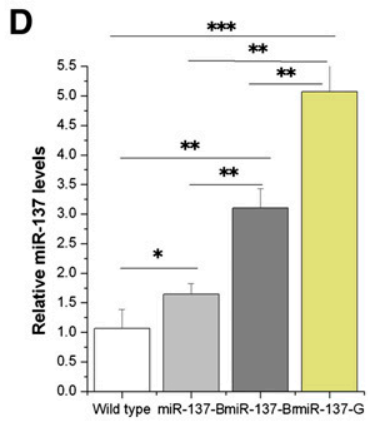

FIGURE 2. Variety of coat color in transgenic mice overexpressing miR-137. (A) PCR genotyping showing the pre-miR-137 band (574 bp) and the EmGFP band (1073 bp). 1, 5, and 7 are miR-137 transgenic mice; + is the positive control using the miR-137 construct as PCR template. (B) Photographs of miR-137-transgenic mice and their wild-type littermates: brown transgenic mouse (left); gray transgenic mice (middle and right). (C) Total melanin content in coat from miR-137 transgenic and wild-type mice: miR-137-B (black coat), miR-137-Br (brown coat), and miR-137-G (gray coat). (D) miR-137 levels in miR-137-transgenic mice of various colors $(n=3)$. Data are mean $\pm \mathrm{SD}, n=3,\left(^{\star}\right) P<0.05,\left({ }^{* *}\right) P<0.01,\left(^{\star *}\right) P<0.001$.

levels did not change under similar treatments. Immunoblot analysis showed MC1R protein levels were significantly increased by 1.49 -fold in cells overexpressing miR-137 plus UV treatment compared with the miR-137 transfected cells (Fig. 4D). These results demonstrated that UV elevates the expression of MC1R in melanocytes but not the expression of $\alpha-\mathrm{MSH}$, suggesting that $\mathrm{UV}$ activates the expression of MC1R and stimulates the keratinocytes or pituitary to secrete $\alpha-\mathrm{MSH}$, which enhances the $\alpha-M S H$ pathway in melanogenesis.

\section{DISCUSSION}

miRNAs play a key role in animal growth and development, as well as the pathogenesis and development of various diseases. Nearly one-third of the genes in mammals were suggested to be regulated by miRNAs (Krek et al. 2005; Lewis et al. 2005; Xie et al. 2005). However, most studies were conducted in cell lines, and few studies on the roles of miRNAs were carried out in vivo in animals. Several miRNAs, including miR-340, mir-137, miR-182, and miR-25, were shown to regulate pigmentation by targeting MITF mRNA (Bemis et al. 2008; Segura et al. 2009; Goswami et al. 2010; Zhu et al. 2010). We showed in this study that pigmentation/coat color was also regulated by miR-137 targeting MITF in transgenic mice. Moreover, we obtained transgenic mice of different coat colors (Fig. 2B), providing a novel animal model for the study of miRNAregulated coat color in wool production and applications.

The regulatory mechanisms involved in coat color are complex and not yet fully understood, although several signaling pathways were implied to affect melanogenesis in cell studies. MITF is essential for melanoblast survival during animal development (Steingrimsson et al. 2004; Vance and Goding 2004). Mutations in MITF gene lead to reduced numbers of melanoblasts and melanocytes and to further pigment defect, which are involved in the melanocytespecific Mitf-M promoter regulated by the SRY-related HMGbox gene 10 (SOX10) or paired box gene 3 (PAX3) transcription factors (De Luca et al. 1988; Goding 2007). A single amino acid change in MITF protein leads to a premature hair graying phenotype (Nishimura et al. 2005). MITF regulates the transcription of TYR, TYRP1, and TYRP2 by binding their promoters (Park and Gilchrest 2002). The mutations of TYR and TYRP1, two enzymes required for melanin synthesis, result in albinism in mice (Oetting et al. 2003). MiR-137 interacts with two of its target sites on the $3^{\prime}$ untranslated region (UTR) of MITF mRNA, causing its destabilization or translational inhibition. In melanoma cell lines, a 15-bp variable nucleotide tandem repeat, located at the $5^{\prime}$ region to the pre-miR-137 sequence, down-regulates the processing and function of miR-137 and thereby affects the expression of MITF (Bemis et al. 2008). We extended the related studies to the regulation of animal coat color by miR-137 in transgenic mice. We observed that miR-137 repressed the expression of MITF protein and reduced the number of active melanocytes in hair bulbs and the expression of TYR, TYRP1, and TYRP2.

Coat color is determined by the amount, sizes, transportation, and distribution of melanin in skin cells. We obtained two kinds of intermediate transitional coat color, brown and gray, by interfering with mouse melanogenesis via overexpression of miR-137. The differential expression of miR-137 in different transgenic lines of mice correlates 
A

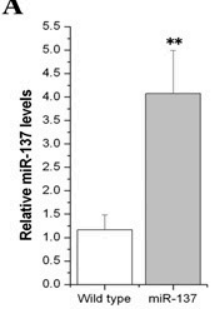

D

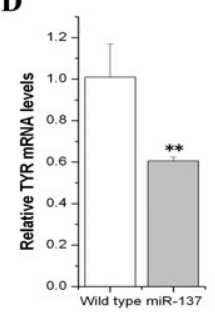

B

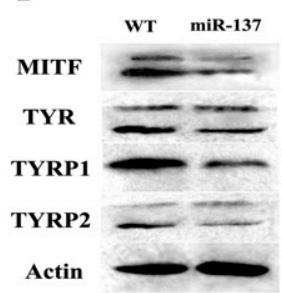

E

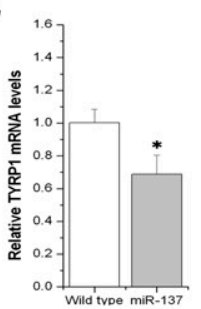

C

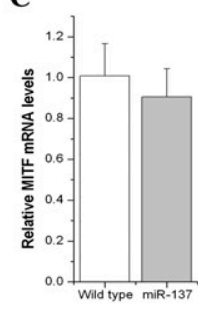

F

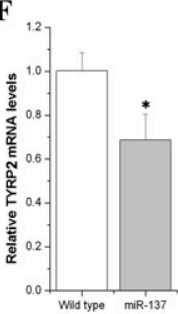

G

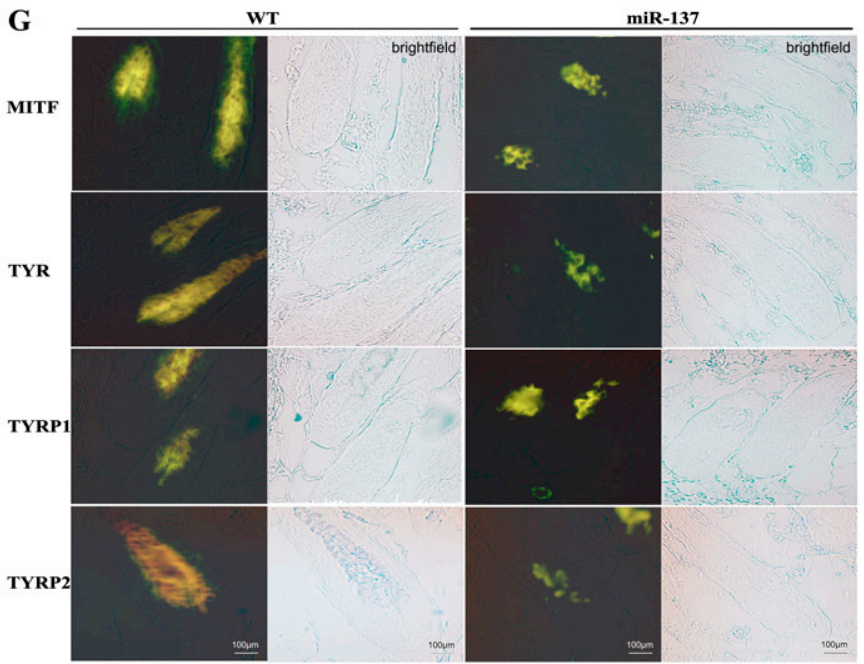

H
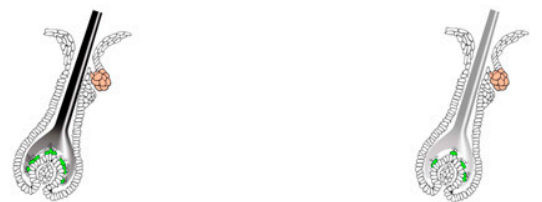

FIGURE 3. MiR-137 transgenic mice displaying altered expression of MITF, TYR, TYRP1 and TYRP2. (A) miR-137 levels in miR-137-transgenic and wild-type mice. (B) Western analysis of MITF, TYR, TYRP1, and TYRP2 expression in miR-137-transgenic mice and their wild-type littermates. $(C-F)$ Real-time PCR on these genes. $(G)$ Immunofluorescence pictures showing the distributions and expressions of MITF, TYR, TYRP1, and TYRP2 proteins. Left is immunofluorescence (FITC). Right is brightfield. $(H)$ Schematic representation of the coat color change. Green cells are activated melanocytes. The scale bar represents $100 \mu \mathrm{m}$.

quantitatively with the altered coat colors. A change of 1.7fold to threefold in miR-137 expressions can lead to an observable alteration in coat color to brown, while a change of three- to fivefold in miR-137 leads to gray (Fig. 2D). Notably, no white color, but the intermediate colors from dark black to gray, was observed in our transgenic mice, suggesting the mechanism of miR-137-regulated coat color is in a complicated and fine-tuning manner in vivo. Other unidentified factors, besides miR-137, may also contribute to the observed phenotypic differences; for example, a constitutive promoter was used in this study. However, we have detected the development of heart, lung, liver, kidney, and brain and did not find any phenotype change except that one of all the transgenic mice showed lower growth compared with the wild-type mice. In order to overcome the negative impact of a constitutive promoter we will use MITF promoter or another specific promoter in future studies.

$\alpha-\mathrm{MSH}$ binding to a single membrane receptor MC1R induces the differentiation of melanocytes and the activation of pigment synthesis (Hirobe and Takeuchi 1977a,b, 1978; Eberle 1988; Hirobe et al. 2004), and MC1R is one of the switch genes for eumelanin and pheomelanin synthesis (Garcia-Borron et al. 2005). Mutations of MC1R gene in many species, including humans, can cause the phenotype of red hair (Goding 2007). Recently, Keiichi Hiramoto used UV B radiation to stimulate the eyes and ears of mice and revealed the nitric oxide (NO)-dependent signaling of cellular response in activating the hypothalamopituitary proopiomelanocortin system, thereby enhancing the hypophysial secretion of $\alpha-\mathrm{MSH}$ to stimulate $\alpha$-MSH-receptorresponsive cells (Hiramoto et al. 2003). The expression of $M C 1 R$ induced $\alpha-M S H$ and enhanced the ability of melanocytes to response to melanogensis (Ortonne 2002). UVB, through NO, can significantly induce the expression of $M C 1 R$ mRNA and protein and can stimulate the keratinocytes to secrete $\alpha$-MSH to enhance the $\alpha-M S H$ pathway in melanogenesis (Dong et al. 2010). Our results showed that $\alpha-\mathrm{MSH}$ and MC1R were increased while miR-137 downregulated MITF in miR-137 transgenic mice (Fig. 4A-C). MC1R was higher in cells overexpressing miR-137 plus UV treatment than in those overexpressing miR-137 alone. But, the $\alpha-\mathrm{MSH}$ level showed no difference under similar conditions (Fig. 4D,E). Based on our data and previous publications, we proposed a model for the avoidance of UV injury in animals. A high level of miR-137 interferes with melanogenesis and reduces coat color. When animals are subjected to UV radiation, the pituitary and keratinocytes secrete $\alpha-\mathrm{MSH}$ and induce the production of MC1R in melanocytes, which activates the $\alpha-M S H$ pathway (Fig. 4F). On the other hand, $\alpha-\mathrm{MSH}$ inhibits the expression of miR137 (Bemis et al. 2008), activates MITF, and produces more melanin in skins to partially compensate for the melanin 
A

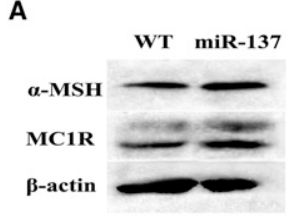

D

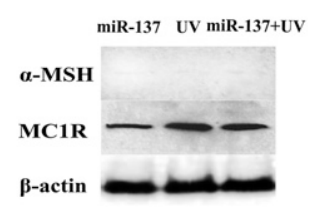

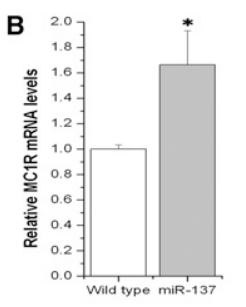
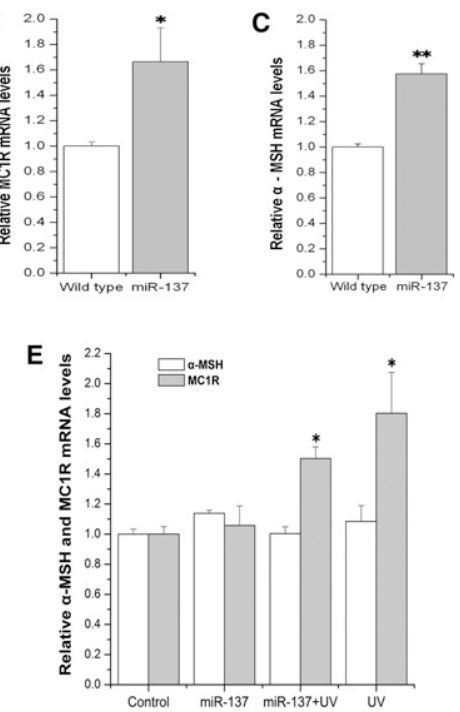

$\mathbf{F}$

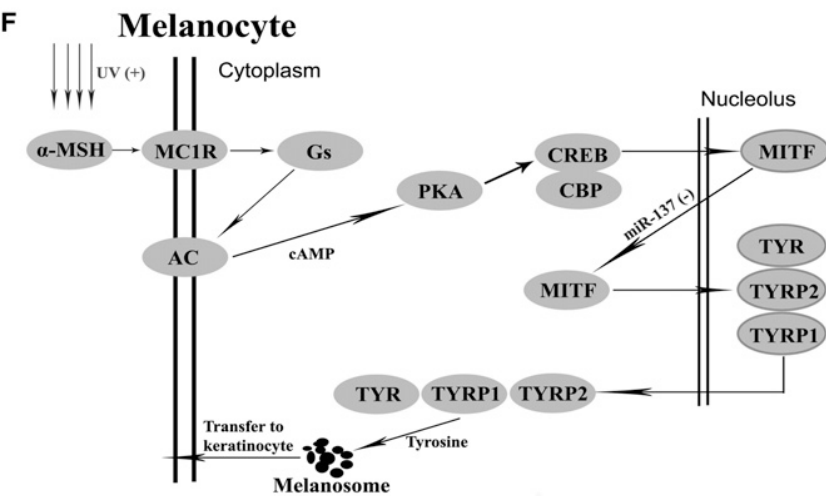

FIGURE 4. Involvement of mir-137 in the $\alpha-\mathrm{MSH}$ signaling pathway. (A) Upstream regulation of miR-137 through $\alpha$-MSH pathway. Western analysis of $\alpha-\mathrm{MSH}$ and MC1R expression in miR-137transgenic mice and their wild-type littermates. $\beta$-actin was used as a protein loading control. $(B, C)$ Real time PCR analysis of $\alpha-\mathrm{MSH}$ and MC1R mRNA expression in miR-137-transgenic mice and their wild-type littermates. $(D)$ Western analysis of $\alpha$-MSH and MC1R expression in the miR-137 overexpression cells (control) and in the cells treated with UV alone and in cells overexpressing miR-137 plus UV treatment. $\beta$-actin was used as a protein loading control. (E) Real time PCR analysis of $\alpha$-MSH and MC1R mRNA expression in the miR-137 overexpression cells and in the cells treated with UV alone and in cells overexpressing miR-137 plus UV treatment and in control. $(F)$ Cartoon showing the biological effects of miR-137 in pigmentation process. $\left.{ }^{*}\right) P<0.05,\left({ }^{*}\right) P<0.01$.

reduction induced by exogenous miR-137. Thus, animals can effectively avoid the injury from UV.

In conclusion, we demonstrated an important role of miR137 in coat color determination in vivo in transgenic mice, providing a novel regulatory pathway of melanogenesis/coat color in animals. The post-transcriptional regulation of MITF by miR-137, which reduces the expression of TYR, TYRP1, and TYRP2, may mildly down-regulate the synthesis of melanin in mouse skin and coat. These results suggest that a single miRNA may play an important role in normal physiological processes in animals. Our transgenic mice can serve as a model system for studying gene regulation by miRNAs during melanogenesis and coat color development. This study provides a potential approach to the production of varieties of coat colors in fiber-producing species.

\section{MATERIALS AND METHODS}

\section{Experimental animal and sample collection}

The housing and care of the mice (C57BL/6J) and the collection of tail and hair samples for use in the described experiments were conducted in accordance with the International Guiding Principles for Biomedical Research Involving Animals (http://www.cioms.ch/ frame 1985 texts of guidelines.htm).

Females were superovulated by intraperitoneal injection with 8 IU pregnant mare serum gonadotropin (PMSG), and $48 \mathrm{~h}$ later, they were injected with 8 IU human chorionic gonadotropin (hCG). In vivo fertilized zygotes were collected $16 \mathrm{~h}$ after hCG from the oviduct ampullae of superovulated females that had been mated with the same strain of males. After removing cumulus cells with $300 \mathrm{IU} / \mathrm{mL}$ hyaluronidase in $\mathrm{M} 2$ medium, zygotes were cultured in M16 medium (Sigma) until use.

\section{Construction of expression vector for miR-137}

An oligonucleotide sequence corresponding to the sequence of the pre-miR-137 was synthesized by Invitrogen and ligated into a mammalian expression vector, pcDNA 6.2-GW/EmGFPmiR (Invitrogen), which contains a CMV promoter driving expression of GFP and miR-137 (Fig. 1B). The pre-miR-137 sequence in our constructs is the same as the endogenous sequence, and it produces miR-137. We have shown that this plasmid is capable of expressing mature miRNA and GFP simultaneously. The GFP expression unit was used to monitor expression of miR-137. To facilitate CMV promoter-driven expression of pre-miR-137, units containing three copies of pre-miR-137, excised with attBI and attBII, were inserted into the attBI- and attBII-opened pcDNA 6.2-GW/EmGFPmiR. The pre-miR-137 construct was transformed into Escherichia coli $(\mathrm{DH} 5 \alpha)$, and the positive colonies were verified by sequencing.

\section{Melanoctye cell culture and transfection of miR-137}

All melanocyte cell cultures used in this study were established in the laboratories of alpaca biology, College of Animal Science and Technology, Shanxi Agricultural University, China. Melanocytes in the culture were maintained in a melanocyte basal medium supplemented with $0.2 \mu \mathrm{g} / \mathrm{mL}$ cholera toxin (Sigma), $0.05 \mathrm{mg} / \mathrm{mL}$ gentamicin, $2.5 \mu \mathrm{g} / \mathrm{mL}$ fungizone, $50 \mu \mathrm{g} / \mathrm{mL}$ bovine pituitary extract (BPE), $0.5 \mu \mathrm{g} / \mathrm{mL}$ hydrocortisone, $1 \mathrm{ng} / \mathrm{mL}$ bFGF, $5 \mu \mathrm{g} / \mathrm{mL}$ insulin, and $10 \mathrm{ng} / \mathrm{mL}$ TPA. They are primary cells, so we used the third passage number for considerations in terms of passage numbers to the outcomes. The transfaction of miR-137 was carried out, according to operation manual of kit (Invitrogen).

\section{Generation and genotyping of miR-137 transgenic mice}

The transgene was released from the plasmid miR-137 by digestion with Spel. The digested product was fractionated by agarose 
gel electrophoresis, and the 5.7-kb fragment was excised from the gel, purified by the QIAEX II Gel Purification Kit (Qiagen), and then resuspended in injection buffer (Sigma) at a concentration of $3 \mathrm{ng} / \mu \mathrm{L}$. The transgene was microinjected into the male pronuclei of the mouse zygotes. Injected embryos were implanted into the oviducts of the pseudopregnant recipient females using a standard protocol approved by the Animal Use Subcommittee of the University Council on Animal Care, the Shanxi Agricultural University. Transgenic lines were maintained by backcrossing with C57BL/ $6 \mathrm{~J}$ mice, which are the control and have stable genetic background. Genotyping was performed by PCR, using primers 2a-mir137F pairing with $2 \mathrm{~b}$-mir137R (for spectinomycin-resistance gene) and GFP2F pairing with 1b-mir137R (for GFP and pre-miR-137 coding sequence), as well as tail DNA as a template. $18 \mathrm{~S}$ served as a control.

\section{The spectrophotometric assay of melanin (alkali-soluble melanin)}

Hair sample suspensions were solubilized in $8 \mathrm{M}$ urea/1 $\mathrm{M}$ sodium hydroxide and cleared by centrifugation at $10,700 \mathrm{~g}$ for $10 \mathrm{~min}$. Chloroform was added to supernatants to remove fatty impurities. Pale yellow aqueous layers containing pheomelanins were cleared by centrifugation at $10,700 \mathrm{~g}$ for $10 \mathrm{~min}$ and analyzed for absorbance at $400 \mathrm{~nm}$ (Hirobe and Takeuchi 1977b; Dong et al. 2010). A400/ $\mathrm{mg}=\mathrm{SpASM}$ (spectrophotometric alkali soluble melanin).

\section{RNA preparation and real-time PCR analysis}

Total RNA was isolated from 12 mouse skin samples (nine transgenic mouse, three wild mouse) using the TRIzol LS Reagent (Invitrogen). The concentration of total RNA was determined using the NanoDrop 1000 spectrophotometer (NanoDrop Technologies), and the integrity of total RNA was confirmed using $1 \%$ agarose gel electrophoresis.

Synthesis of cDNA for real-time PCR analysis of miR-137 expression in mice skin and cultured melanocytes was performed using the NCode miRNA q-RT-PCR kit according to manufacturer's instructions (Invitrogen). Briefly, the total RNA was polyadenylated using poly A polymerase and ATP. Complementary DNA was generated using the NCode universal reverse primer, and real-time PCR was performed using the universal qPCR primer and a sequence-specific forward primer for miR-137. All reactions were performed in triplicate on the Stratagene Mx3005P Real-Time QPCR system. Quantification of miR-137 transcript abundance was performed using the comparative threshold cycle (CT) method. The abundance of miR-137 was normalized relative to that of U6 snRNA.

Real-time PCR analysis of mRNA abundance in miR-137 transgenic group and control group was performed for MITF and three enzymes involved in melanin biosynthesis (TYR, TYRP1, and TYRP2) whose transcription is known to be stimulated by MITF. Real-time PCR was performed as described previously (Segura et al. 2009; Goswami et al. 2010; Zhu et al. 2010). The expression of mRNA for target genes of interest (MITF, TYR, TYRP1, and TYRP2) was normalized relative to the abundance of $18 \mathrm{~S}$ rRNA. All primer sequences are listed in Supplemental Table S1.

\section{Immunofluorescence analysis}

Free-floating sections of mice skin were washed three times, for 3 min each, in 0.1 M PBS and were then incubated at room tem- perature in $3 \%$ hydrogen peroxide for 15 min to block the action of any endogenous peroxidase. After washing with $0.1 \mathrm{M}$ PBS three times for $15 \mathrm{~min}$, there was a 10 -min boiling in $\mathrm{H}_{2} \mathrm{O}$ containing $0.01 \mathrm{M}$ citric acid. This was followed by a 20-min immersion in PBS containing 5\% BSA (bull serum albumin) at $37^{\circ} \mathrm{C}$. Afterward, sections were incubated for $15-24 \mathrm{~h}$ at $4^{\circ} \mathrm{C}$ in one of the primary antibody solutions-anti-MITF (C17, 1:200; Santa Cruz Biotechnology), anti-TYR (H109, 1:200; Santa Cruz Biotechnology), anti-TYRP1 (H90, 1:200; Santa Cruz Biotechnology), or antiTYRP2 (TYRP2 H150, 1:500; Santa Cruz Biotechnology)—and for $30 \mathrm{~min}$ at room temperature. Following three washes in $0.1 \mathrm{M}$ PBS for $5 \mathrm{~min}$ each, sections were incubated with the secondary antibodies FITC-anti-goat and FITC-anti-rabbit IgG (1:500 dilution) for $20-30 \mathrm{~min}$ at $37^{\circ} \mathrm{C}$. After washing with $0.1 \mathrm{PBS}$ three times for $15 \mathrm{~min}$, the immunofluorescence was then observed under a fluorescence microscope (Leica).

In negative controls, PBS was substituted for the primary antibody in the first reaction.

\section{Western blot analysis for MITF}

Total protein extracts from the mouse tails were done using a protein extraction kit (RIPA Lysis Buffer, Beyotime) according to the manufacturer's instructions. Protein concentrations were measured by the BCA method using bovine serum albumin as the standard. Extracts were heat denatured at $95^{\circ} \mathrm{C}$ for $5 \mathrm{~min}$, and equal amounts $(100 \mu \mathrm{g} / \mathrm{lane})$ of protein from each sample were separated by $10 \%$ SDS-PAGE and electroblotted onto nitrocellulose membranes. Western immunoblotting was carried out. Primary antibodies were used at the following dilutions: anti-MITF (C17, 1:200; Santa Cruz Biotechnology), anti-TYR (H109, 1:200; Santa Cruz Biotechnology), anti-TYRP1 (H90, 1:200; Santa Cruz Biotechnology), anti-TYRP2 (DCT H150, 1:500; Santa Cruz Biotechnology), and anti- $\beta$-actin (1:1000; CWBIO). Dilutions were all in fresh $5 \%$ skim milk blocking buffer, and incubations were overnight at $4^{\circ} \mathrm{C}$. After washing in TBS, $0.1 \%$ with Tween 20 , the appropriate horseradish peroxidase conjugated secondary antibody (Zymed Laboratories) was incubated with the blot for $1 \mathrm{~h}$ at room temperature (1:5000 in 3\% blocking buffer). Following washing, the blot was exposed to Supersignal West Pico (TIANGEN). The intensity of the signals for MITF was quantified using Image-Pro Plus Software, version 6.0 (Media Cybernetics), and normalized relative to values obtained for $\beta$-actin. All experiments were performed in triplicate.

\section{Statistical analysis}

The differences in abundance of miR-137 and mRNA analyzed (MITF, TYR, TYRP1 and TYRP2) and protein abundance for them in miR-137 overexpressing mice and control mice ( $n=3$ replicates) were determined by analysis of variance.

\section{SUPPLEMENTAL MATERIAL}

Supplemental material is available for this article.

\section{ACKNOWLEDGMENTS}

We thank Shanxi Medical University for assistance in the housing and care of mice, TianFu Liu for the generation and maintenance of transgenic mice, and JianBo Yao for editing the manuscript. This work was sponsored by the National Natural Science Foun- 
dation of China (30571070), Youth Foundation of Shanxi Province (2012021028-3), and a grant from the Ministry of Agriculture of the People's Republic of China (2011-Z33).

Received April 22, 2012; accepted June 11, 2012.

\section{REFERENCES}

Bauer GL, Praetorius C, Bergsteinsdottir K, Hallsson JH, Gisladottir BK, Schepsky A, Swing DA, O'Sullivan TN, Arnheiter H, Bismuth $\mathrm{K}$, et al. 2009. The role of MITF phosphorylation sites during coat color and eye development in mice analyzed by bacterial artificial chromosome transgene rescue. Genetics 183: 581-594.

Bemis LT, Chen R, Amato CM, Classen EH, Robinson SE, Coffey DG, Erickson PF, Shellman YG, Robinson WA. 2008. MicroRNA-137 targets microphthalmia-associated transcription factor in melanoma cell lines. Cancer Res 68: 1362-1368.

Bentley NJ, Eisen T, Goding CR. 1994. Melanocyte-specific expression of the human tyrosinase promoter: Activation by the microphthalmia gene product and role of the initiator. Mol Cell Biol 14: 7996-8006.

Calin GA, Croce CM. 2006. MicroRNA signatures in human cancers. Nat Rev Cancer 6: 857-866.

De Luca M, D’Anna F, Bondanza S, Franzi AT, Cancedda R. 1988. Human epithelial cells induce human melanocyte growth in vitro but only skin keratinocytes regulate its proper differentiation in the absence of dermis. J Cell Biol 107: 1919-1926.

Dong Y, Cao J, Wang H, Zhang J, Zhu Z, Bai R, Hao H, He X, Fan R, Dong C. 2010. Nitric oxide enhances the sensitivity of alpaca melanocytes to respond to $\alpha$-melanocyte-stimulating hormone by up-regulating melanocortin-1 receptor. Biochem Biophys Res Commun 396: 849-853.

Eberle AN. 1988. The melanotropins: Chemistry, physiology and mechanisms of action, pp. 73-78. S. Karger, Basel, Switzerland.

Fitzpatrick TB. 1965. Mammalian melanin biosynthesis. Trans St Johns Hosp Dermatol Soc 51: 1-26.

Fitzpatrick TB, Breathnach AS. 1963. The epidermal melanin unit system [in German]. Dermatol Wochenschr 147: 481-489.

Garcia-Borron JC, Sanchez-Laorden BL, Jimenez-Cervantes C. 2005. Melanocortin-1 receptor structure and functional regulation. Pigment Cell Res 18: 393-410.

Garzon R, Fabbri M, Cimmino A, Calin GA, Croce CM. 2006. MicroRNA expression and function in cancer. Trends $\mathrm{Mol}$ Med 12: $580-587$.

Goding CR. 2007. Melanocytes: The new black. Int J Biochem Cell Biol 39: $275-279$.

Goswami S, Tarapore RS, TeSlaa JJ, Grinblat Y, Setaluri V, Spiegelman VS. 2010. MicroRNA-340-mediated degradation of microphthalmia-associated transcription factor mRNA is inhibited by the coding region determinant-binding protein. J Biol Chem 27: 20532-20540.

Hemesath TJ, Steingrímsson E, McGill G, Hansen MJ, Vaught J, Hodgkinson CA, Arnheiter H, Copeland NG, Jenkins NA, Fisher DE. 1994. Microphthalmia, a critical factor in melanocyte development, defines a discrete transcription factor family. Genes Dev 8: 2770-2780.

Hiramoto K, Yanagihara N, Sato EF, Inoue M. 2003. Ultraviolet B irradiation of the eye activates a nitric oxide-dependent hypothalamopituitary proopiomelanocortin pathway and modulates functions of $\alpha$-melanocyte-stimulating hormone-responsive cells. I Invest Dermatol 120: 123-127.

Hirobe T, Takeuchi T. 1977a. Induction of melanogensis in the epidermal melanoblasts of newborn mouse skin by MSH. J Embryol Exp Morphol 37: 79-90.

Hirobe T, Takeuchi T. 1977b. Induction of melanogenesis in vitro in the epidermal melanoblasts of newborn mouse skin by MSH. In Vitro 13: 311-315.

Hirobe T, Takeuchi T. 1978. Changes of organelles associated with the differentiation of epidermal melanocytes in the mouse. J Embryol Exp Morphol 43: 107-121.
Hirobe T, Takeuchi S, Hotta E. 2004. The melanocortin receptor-1 gene but not the proopiomelanocortin gene is expressed in melanoblasts and contributes their differentiation in the mouse skin. Pigment Cell Res 17: 627-635.

Krek A, Grün D, Poy MN, Wolf R, Rosenberg L, Epstein EJ, MacMenamin P, Piedade ID, Gunsalus KC, Stoffel M, et al. 2005. Combinatorial microRNA target predictions. Nat Genet 37: 495500.

Kurita K, Nishito M, Shimogaki H, Takada K, Yamazaki H, Kunisada T. 2005. Suppression of progressive loss of coat color in microphthalmia-vitiligo mutant mice. J Invest Dermatol 125: 538-544.

Lewis BP, Burge CB, Bartel DP. 2005. Conserved seed pairing, often flanked by adenosines, indicates that thousands of human genes are microRNA targets. Cell 120: 15-20.

Lin YP, Hsu FL, Chen CS, Chern JW, Lee MH. 2007. Constituents from the Formosan apple reduce tyrosinase activity in human epidermal melanocytes. Phytochemistry 68: 1189-1199.

Lu J, Getz G, Miska EA, Alvarez-Saavedra E, Lamb J, Peck D, SweetCordero A, Ebert BL, Mak RH, Ferrando AA, et al. 2005. MicroRNA expression profiles classify human cancers. Nature 435: 834-838.

Nishimura EK, Granter SR, Fisher DE. 2005. Mechanisms of hair graying: Incomplete melanocyte stem cell maintenance in the niche. Science 307: 720-724.

Oetting WS, Fryer JP, Shriram S, King RA. 2003. Oculocutaneous albinism type 1: The last 100 years. Pigment Cell Res 16: 307-311.

Ortonne JP. 2002. Photoprotective properties of skin melanin. Br J Dermatol 146: 7-10.

Park HY, Gilchrest BA. 2002. More on MITF. J Invest Dermatol 119: 1218-1219.

Schallreuter KU, Kothari S, Chavan B, Spencer JD. 2008. Regulation of melanogenesis: Controversies and new concepts. Exp Dermatol 17: 395-404.

Segura MF, Hanniford D, Menendez S, Reavie L, Zou X, Alvarez-Diaz S, Zakrzewski J, Blochin E, Rose A, Bogunovic D, et al. 2009. Aberrant miR-182 expression promotes melanoma metastasis by repressing FOXO3 and microphthalmia-associated transcription factor. Proc Natl Acad Sci 106: 1814-1819.

Sonkoly E, Wei T, Janson PC, Saaf A, Lundeberg L, Tengvall-Linder M, Norstedt G, Alenius H, Homey B, Scheynius A, et al. 2007. MicroRNAs: Novel regulators involved in the pathogenesis of psoriasis? PLoS ONE 2: e610. doi: 10.1371/journal.pone.0000610.

Steingrimsson E, Copeland NG, Jenkins NA. 2004. Melanocytes and the microphthalmia transcription factor network. Annu Rev Genet 38: $365-411$.

Vance KW, Goding CR. 2004. The transcription network regulating melanocyte development and melanoma. Pigment Cell Res 17: 318-325.

Xie X, Lu J, Kulbokas EJ, Golub TR, Mootha V, Lindblad-Toh K, Lander ES, Kellis M. 2005. Systematic discovery of regulatory motifs in human promoters and 3' UTRs by comparison of several mammals. Nature 434: 338-345.

Yasumoto K, Yokoyama K, Shibata K, Tomita Y, Shibahara S. 1994. Microphthalmia-associated transcription factor as a regulator for melanocyte-specific transcription of the human tyrosinase gene. Mol Cell Biol 14: 8058-8070.

Yasumoto K, Yokoyama K, Takahashi K, Tomita Y, Shibahara S. 1997. Functional analysis of microphthalmia-associated transcription factor in pigment cell specific transcription of the human tyrosinase family genes. J Biol Chem 272: 503-509.

Yi R, Poy MN, Stoffel M, Fuchs E. 2008. A skin microRNA promotes differentiation by repressing "stemness." Nature 452: 225-229.

Zhang W, Wu J, Li J, Midori Y. 2007. A subset of skin-expressed microRNAs with possible roles in goat and sheep hair growth based on expression profiling of mammalian microRNAs. OMICS 11: $385-396$.

Zhu Z, He J, Jia X, Jiang J, Bai R, Yu X, Lv L, Fan R, He X, Geng J, et al. 2010. MicroRNA-25 functions in regulation of pigmentation by targeting the transcription factor MITF in alpaca (Lama pacos) skin melanocytes. Domest Anim Endocrinol 38: 200-209. 

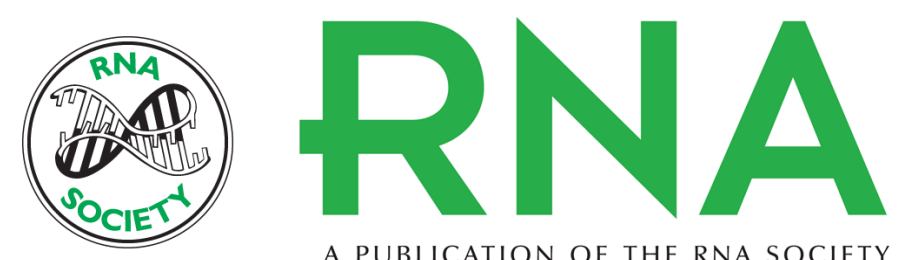

A PUBLICATION OF THE RNA SOCIETY

\section{Coat color determination by miR-137 mediated down-regulation of microphthalmia-associated transcription factor in a mouse model}

Changsheng Dong, Haidong Wang, Linli Xue, et al.

RNA 2012 18: 1679-1686 originally published online July 30, 2012

Access the most recent version at doi:10.1261/rna.033977.112

Supplemental
Material http://rnajournal.cshlp.org/content/suppl/2012/07/05/rna.033977.112.DC1

References This article cites 38 articles, 8 of which can be accessed free at:

http://rnajournal.cshlp.org/content/18/9/1679.full.html\#ref-list-1

License

Email Alerting Receive free email alerts when new articles cite this article - sign up in the box at the Service top right corner of the article or click here. 